\title{
A trajetória silenciosa de pessoas portadoras do HIV contada pela história oral
}

\author{
The silent itinerary of people with HIV \\ told through oral history
}

M aria Rita de Cassia Barreto deAlmeida ${ }^{1}$

LilianaM ariaLabronici ${ }^{2}$

Este artigo éum recorte da dissertação demestrado intitulada"A trajetória silenciosa de pessoas portadoras do HIV contada pelahistória oral" defendida em 18 de dezembro de 2004.

'Pontifícia Universidade

Católica do Paraná. Rua Imaculada Conceição 1155,

Prado Velho. 80215-901

Curitiba PR.

mariarita.cassia@yahoo.com.br

${ }^{2}$ Departamento de

Enfermagem daUFPR.
Abstract The emergence of AIDS as a social and historical phenomenon has brought along with it specters held in social imagination, aggravating the concept of plague, generating strong feelings and prejudice, becoming a stigma. Such factors ultimately affect HIV bearers' well being. Thus, this study aims to understand the dimension of the problem of HIV bearers who have not seeked treatment in the $\mathrm{N}$ ational $\mathrm{H}$ ealth System and the reasons which make this search so difficult. The adopted methodological approach was thematic oral accounts. Five HIV bearers collaborated in this study. By using content analysis, we observed that the study participants do not go to Health Units near their homes fearing to be identified, especially since they know they will certainly meet peoplefrom their neighborhood at the health units who do not know about their HIV diagnosis. Because of this fear, they anticipate they will suffer discrimination and stigmatization - due to the disease's social significance - and so, to protect themselves, they choose a secrecy that keeps them from trusting anyoneand from seeking heal th care, thus increasing their personal suffering and vulnerability to develop AIDS.

Key words Stigma, Health system, Nursing
Resumo 0 surgimento da AIDS como fenômeno social ehistórico carregou consigo os espectros construídos no imaginário social, recrudescendo o conceito de peste, mobilizando sentimentos e preconceitos, tornando-se ela mesma um grande estigma. Fatores que afetam de maneira fundamental 0 bem-estar de pessoas vivendo com o HIV. E para compreender a dimensão do problema das pessoas que vivem com o HIV que não procuraram os serviços do SUS para o acompanhamento de sua saúde, propusemo-nos a realizar este estudo tendo como objetivo apreender os motivos que dificultam essa procura. 0 referencial metodológico adotado foi história oral temática. Os colaboradores do estudo foram cinco pessoas portadoras do HIV. U tilizando a análise de conteúdo, observamos que os colaboradores não procuram as U nidades de Saúde próximas às suas casas pelo medo de serem identificados, principalmente quando sabem que nesses serviços irão encontrar pessoas de seu convívio social para quem não foi revelado seu diagnóstico de HIV. Devido a esse medo, antecipam que vão sofrer de discriminação e estigmatização - em função da representação social da doença - e, assim, para se proteger, escolhem o segredo que os impede de confiar em alguém ou procurar cuidados para a sua saúde, aumentando seu sofrimento pessoal esua vulnerabilidadepara adoecer deAIDS. Palavras-chave Estigma, Sistema de saúde, Enfermagem 
Introdução

A AIDS, ao se fazer presente no mundo moderno, levantou a ameaça de uma crise global de rápida disseminação e agravamento, exigindo respostas ea necessidade premente de criação de recursos econômicos, políticos, sociais e psicológicos que dessem conta de uma problemática com tal magnitude.

Essa crise instigou principalmente nossa capacidadedelidar deforma humanitária com uma doença repleta desímbolos, significados, imagens imprecisas, falaciosas e que estimularam atitudes descomedidas de pânico, negação, intolerância e discriminação às pessoas atingidas por ela.

Assim, diante dessefenômeno profundamente alterador, avanços significativos aconteceram, ações foram implantadas, respostas foram surgindo, mitos foram sendo desbancados e se acumularam experiências, reflexões e novas tecnologias de prevenção e assistência e de defesa dos direitos humanos.

No entanto, o que parece ficar claro é que, a despeito desses avanços, dentreeleso advento dos antiretrovirais que melhoraram a qualidade de vida das pessoas, afastando-as da grande letalidade da doença, persevera a triste constatação de que a epidemia ainda é soberana e que a relação do conviver com o HIV e a AIDS continua cobrando um alto custo em sofrimento humano advindo do estigma, preconceito e discriminação que a doença impõe.

A existência detais questõesfaz com quemuitas pessoas afetadas pela AIDS caminhem solitária e silenciosamente, limitadas em suas possibilidades de direitos e de acesso aos meios de proteção, promoção e assistência, obrigando-as muitas vezes a esconder sua condição sorológica pel o medo dese expor ede padecer de preconceito ou discriminação, respostas provocadas pelo estigma.

E, para compreender a dimensão do problema das pessoas que vivem com o HIV ea AIDS que não procuraram os serviços do Sistema ú nico de Saúde (SUS) para o acompanhamento de sua saúde, propusemo-nos a realizar este estudo tendo como objetivo apreender os motivos que dificultam essa busca.

Os relatos e reflexões surgidos nesta investigação permitiram-nos delinear o movimento de suas relações sociais, os significados que instituíram às suas vidas, principalmente quanto à sua trajetória de vida após o conhecimento da sorologia reagente para o HIV. E, para engendrar na ode obscura dos colaboradores que não procu- raram os serviços na busca aos cuidados de sua saúde, alvoreceu a pesquisa qualitativa que permitiu um aprofundamento nos matizes enas singularidades procedentes deuma realidade social e humana equefalou através defaces ocultas, quais foram as situações nas suas vidas que as levaram a'escolher' estecaminho. Como referencial metodológico, empregou-se a história oral temática, tendo sido entrevistadas cinco pessoas soropositivas residentes em Curitiba - Paraná.

\section{A contextualização social daAIDS}

A sociedade, diante de uma nova doença que se disseminava rapidamente, que apresentava uma alta taxa de letalidade e suscitava intensas emoções de pânico, de medo e de contágio, precisava ser prontamente caracterizada e entendida a fim de minimizar as conseqüências de um mal quejá se imaginava abolido da experiência humana: a 'peste' ${ }^{1}$. Rapidamente, a partir de uma interrogação científica sobre os doentes, cujo número na época era muito limitado, produziu-se um discurso no qual se configurou a sensação de um risco iminente que repercutia sobre toda a coletividade, questionando nossos modos de vida e nossos valores².

Tal questão diz respeito à construção social da AIDS, pois ao se fazer presente para o mundo humano, este precisava iniciar um processo de construção do código deinterpretações desta nova realidade. A questão imediata era estabelecer símbolos que, partilhados pela sociedade, Ihe permitissem a comunicação a respeito da mesma, a fim de decifrá-la ${ }^{1}$. 0 fato interessanteda AIDS équea construção do sentido e a elaboração do seu conhecimento comum, produzido pela sociedade e pela opinião pública, aconteceram paralelamente à codificação médica, situação a que talvez nunca tenhamos assistido $0^{1,2}$.

Assim, diante do desconhecido, a sociedade produziu representações apoiadas na idéia de doença contagiosa, incurável e mortal, recrudescendo o conceito de'peste', cujo significado representava uma ameaça extrema à sociedade, atrelada a atitudes de evitamento daquele que a portava. Além desses entendimentos, a AIDS era uma doença que levava à deformação física e estava associada a grupos considerados discriminadose marginalizados, como os homossexuais, usuários de drogas injetáveis e as prostitutas. Essa forma de representá-la serviu para retirá-la do campo das doenças, transmutando-a para o campo das doenças malignas, mobilizando sentimentos 
e preconceitos arraigados e evocando comportamentosepolíticas discriminatórias, principalmente em relação aos grupos supracitados. Assim a AIDS conglomerou vários estigmas, transformando-se ela mesma em um grande estigma?.

Além dos entendimentos da peste e do estigma, as representações construídas para significar a AIDS tiveram, igualmente, como base as crenças e interpretações morais, principal mente relacionadas à sexualidade, que acabaram instituindo valores para explicar a origem da situação que provocou a infecção. Esse posicionamento moral da sociedade acabou inscrevendo culpa e responsabilidade pelo fato de uma pessoa estar doente deAIDS ou ser portadora do HIV, dirigindo-Iheo rótulo de culpada, pois o seu estilo de vida rompeu com os comportamentos socialmente aceitáveis e, assim, a doença reafirma seu caráter de pena e castigo.

Por conseguinte, os aspectos metafóricos atribuídos a ela alijam a experiência da pessoa soropositiva, que se vê merecedora dos castigos de Deus, cujos pecados devem ser expiados pelos atos transgressores que cometeu ${ }^{4,5}$, e a morte, que antes era idealizada, agora se concretiza próxima e real, merecida e providencial em razões do seu modo de vida como causa da infecção pelo HIV. Diante desse momento, permeado por um conjunto de aspectos como medo, morteeculpa, além de todo o cabedal das metáforas discriminatórias quecarrega consigo, a pessoa fica fragilizada, pois vivencia situações de ameaça à sua integralidade física, emocional e social.

Em função dessas representações, advindas do preconceito e da ignorância, as pessoas com 0 HIV eaAIDS vivenciam emoções singulares permeadas de sofrimento dentro de um contexto re pleto de significados, entre os quais: o medo do abandono, de ser julgado e de revelar sua identidade social, a culpa pelo adoecimento, a impotência, a fuga, a clandestinidade, a omissão, a exclusão e o suicídio, originados e construídos pelo real convívio com o social que reforça os hábitos e as expectativas e que estão profundamente enraizados numa sociedade preconceituosa ${ }^{6,7}$.

Destarte, considerando as principais crenças explicativas que tipificaram a história social da epidemia da AIDS agregadas aos domínios do estigma e da discriminação, podemos entender como grupos e indivíduos sofrem de modo inexorável os verberes desta doença e que oprimem àqueles que são acometidos ou os mais vulneráveis à infecção pelo HIV.

Registre-se que as repercussões negativas do estigma e da discriminação conduzem em longo prazo a uma instabilidade ainda maior, pois novas enovas infecções continuarão a acontecer, uma vez que os obstácul os sociais que se têm construído não poderão de forma alguma conter a epidemia. Se o objetivo é de se ter respostas mais efetivas no controle dela, isto exige um entendimento maior da forma como o estigma é construído, sentido e experienciado.

\section{Compreendendo o estigma relacionado ao HIV eà AIDS}

A discussão em torno do estigma parte do trabaIho clássico de Goffman ${ }^{8}$, quedefineestigmacomo um atributo que tem um significado depreciativo de quem o porta e que a sociedade utiliza-o para desqualificar a pessoa, uma vez quetal atributo é entendido como defeito, fraqueza ou desaprovação. 0 autor enuncia que a pessoa estigmatizada carrega uma identidade marcada e deteriorada, associada a atributos que levam ao descrédito. Logo, os estigmas de uma pessoa ou grupo acabam detonando reações e comportamentos de evitação erepulsa, eatémesmo reações violentas. Tal questão éfruto de um processo social ehistórico das relações sociais que se utiliza para analisar as pessoas consideradas menos valorizadas, criando assim, rótulos que estigmatizam, discriminam e excluem certos grupos.

0 estigma pode apresentar-se numa dupla perspectiva: a primeira acontece quando há uma discrepância entre a identidade social real da pessoa e sua identidade virtual. Essa pessoa é então considerada desacreditada. A segunda possibilidade na vida daquele que porta o estigma se dá quando a sua diferença não está aparente enão se tem dela um conhecimento prévio. Nesse caso, ela é uma pessoa desacreditável ${ }^{8}$.

A questão que Goffman ${ }^{8}$ coloca é que, nessa condição, há a necessidade da manipulação da informação sobre o defeito para que o mesmo não seja descoberto. Então, na relação com outras pessoas, o indivíduo que porta um estigma esconderá informações sobre a sua condição, recebendo e aceitando um tratamento fundamentado em falsas opiniões a seu respeito. Segundo 0 autor, a falta de um intercâmbio saudável entre os atores sociais faz com que a pessoa estigmatizada se auto-isole, tornando-se desconfiada, deprimida, hostil, ansiosa e confusa, pois não se sente segura em relação à maneira como os outros a identificarão ereceberão, surgindo a sensação de nunca saber aquilo que os outros estão realmente pensando dela. Quando os estigmas 
são muito visíveis ou violentos, que chegam a ferir a sua dignidade, o desequilíbrio resultante na interação pode ter um efeito arrasador naquele que recebe o papel de estigmatizado.

Acrescente-se a este conceito novos entendimentos em relação ao estigma, como sendo não apenas uma construção social da realidade que desvaloriza relacionamentos deum indivíduo perante 0 outro, mas, também, como processos sociais profundamente enraizados nas relações de poder edominação, criando e reforçando as desigual dades sociais. Isso faz com que grupos se sintam superiores e outros, desvalorizados ${ }^{9}$.

Dessa forma, é possível ver a estigmatização desempenhando um papel chave na transformação da diferença em desigualdade, em relação a qualquer dos eixos da desigualdade estrutural presente na diferença de classe, gênero, etnia ou sexualidade, as quais têm maior relação com o HIV eà AIDS. Destaca-se, ainda, quea estigmatização não ocorre de maneira abstrata; pelo contrário, ela faz partede complexas lutas pelo poder que estão no coração da vida social, ou seja, o estigma é empregado por atores sociais reais e identificáveis que buscam legitimar o seu status dominante dentro das estruturas de desigualdadesocial existente?.

Tais questões nos ajudam a compreender como a estigmatização faz as desigual dades pare cerem aceitáveis, uma vez que ela instituiu uma hierarquia social entre os estigmatizados e não estigmatizados, criando e reforçando, de forma sincrônica, a exclusão social' ${ }^{9}$.

Em relação ao HIV e à AIDS, é oportuno re lembrar que em 1987 Jonathan M ann chamou a atenção para a existência detrês fases da epidemia daAIDS: a epidemia da infecção pelo HIV - uma disseminação silenciosa e imperceptível do vírus; a segunda, a própria epidemia da AIDS - manifesta pelo aparecimento dos sintomas de doença infecciosa, e a terceira, potencialmente a mais explosiva, como a epidemia das respostas sociais, culturais, econômicas e políticas à AIDS, caracterizada por reações carregadas de estigma, discriminação epor vezes negação er epulsa da coletividade $^{10}$.

De Bruyn apud Programa Conjunto das Nações Unidas sobre o VIH/SIDA ${ }^{10}$ identificou re centemente cinco fatores que contribuem ao estigma relacionado com o HIV e à AIDS, que são: (1) o fato deque o HIV/AIDS seja uma enfermidade que ameaça a vida; (2) o fato de que as pessoas tenham medo de contrair o HIV; (3) a associação da doença a comportamentos (como relações sexuais entre homens e o consumo de drogas injetáveis) queainda são objeto de estigma em muitas sociedades; (4) o fato de que muitas vezes se pensa que pessoas que vivem com o H IV ea AIDS são responsáveis por terem contraído a doença; (5) as crenças religiosas ou morais que levam algumas pessoas a pensar queter o HIV ou a AIDS é um resultado de uma falta moral (como promiscuidade ou as relações sexuais "desviantes") e que merecem castigo.

0 estigma e a discriminação relacionados ao HIV eàAIDS, complementam Parker eAggleton, [favor complementar com número arábico referente à referência bibliográfica] podem ser percebidos esentidos em doisníveis: o plano individual, retratado pela vivência pessoal de atores sociais específicos e no plano social, que pode ser retratado como a experiência coletiva. N este último, as leis, as regras, as políticas públicas e os procedimentos administrativos, decretados por muitos países com o fito de controlar as ações dos indivíduos e segmentos da população afetados pelo HIV epela AIDS, têm demonstrado que essas medidas incrementam ereforçam o estigma às pessoas que vivem com a doença, bem como àqueles que estão mais vulneráveis para contrair 0 vírus. Essas medidas incluem legislação para: (1) a testagem sistemática e obrigatória do HIV a grupos e indivíduos; (2) a proibição de certas ocupações e formas de em rego para pessoas com HIV; (3) 0 exame médico, 0 isolamento, a detenção e a imposição ao tratamento dos infectados; (4) as limitações das viagens internacionais e migrações; e (5) a restrição de certos comportamentos tais como o uso de drogas injetáveis e a prostituição 10:12.

No caso de outras doenças infecciosas essas respostas podem ser justificadas, continuam os autores, mas no caso do HIV e da AIDS, por ser uma doença que carrega consigo uma carga enorme de estigma, essas medidas dão lugar a repostas punitivas que discriminam ainda mais as pessoas que vivem com o HIV e a AIDS, e podem levar os infectados e os que estão mais vulneráveis a uma maior clandestinidade.

No plano individual, como refereZampiere, a roupagem simbólica assumido pelo estigma da AIDS passou a ser um dos grandes obstáculos que impedem as pessoas de revelarem seu status sorológico pelo medo do abandono, do julgamento e de reações hostis ou negativas por parte dos outros, o que pode impedir algumas delas de ter acesso aos serviços de saúde e, por conseguinte, melhorar a qualidade de suas vidas. Também resultam evidências de auto-estigmatização ou de vergonha, o que pode conduzir à depressão, retraimento e a sentimentos autodestrutivos. Estes sentimentos podem resultar 
em auto-isolamento e exclusão da vida social e de relacionamentos sexuais, e em circunstâncias extremas até chegar ao suicídio ${ }^{11}$. Tais considerações levam algumas pessoas a não se sentirem mais parte da sociedade civil não conseguindo procurar os serviços de saúde e apoio a que têm direito. A este fenômeno Daniel ${ }^{12}$ chamou de morte social.

As pesquisas do Programa Conjunto das Nações Unidas sobre o VIH/SIDA apontam alguns caminhos para promover respostas mais eficaz com vistas a minimizar o estigma e a discriminação relacionada ao HIV eà AIDS. A ação deve ser realizada em vários eixos, quais sejam: comunicação e educação para facultar uma maior compreensão na construção denovos conceitos e idéias de relevância à estigmatização e à discriminação relacionadas ao HIV e à AIDS, proporcionado, assim, novas maneiras de aprender os processos de mudanças, movimentos sociais e transformações culturais, bem como o questionamento das estruturas de igualdade e desigual dade em qualquer cenário social; ação e intervenção para estabelecer um contexto depolíticas mais eqüitativo, eum procedimento jurídico, para exigir a observância dos direitos das pessoas que vivem com o HIV ea AIDS, no sentido de pedir contas aos governos, empresários, instituições e indivíduos, com o intuito de reparar ou se opor aos atos discriminatórios.

O objetivo fundamental ébuscar um esforço conjunto rumo a uma ação baseada na compreensão, uma ação que promova modelos de conduta mais igualitários e progressistas em relação ao gênero e à sexualidade, e que colaborem no sentido de melhorar o modo em que vivemose nos relacionamos uns com os outros ${ }^{11}$.

\section{O descortinar dos resultados}

\section{Percurso metodológico}

Para empreender o objetivo desta investigação, optou-se como estratégia metodológica a história oral, mais especificamentea história oral temática, que é uma metodologia voltada à experiência vivencial daquele que narra ${ }^{13,14}$, ou na busca de informações factuais ${ }^{14}$. Para M eihy, os trabalhos em história oral devem seguir alguns procedimentos e princípios, tais como: a escolha das colônias, a formação de rede, a entrevista, a transcrição, a conferência, o uso autorizado dos textos e 0 arquivamento dos depoimentos. Nesse caso, estabeleceu-se como colônia pessoas portadoras do HIV que não procuraram os serviços na busca aos cuidados de sua saúde. Já a escolha da rede, segundo M eihy, segue uma especificidade maior, pois é uma subdivisão da colônia que funciona como indicativo de como as entrevistas devem ser articuladas. Portanto, a rede foi composta de pessoas que não procuraram os serviços para acompanhamento de sua infecção e que já conheciam a sua sorologia há mais de um ano.

Considerando que os colaboradores da pesquisa estavam ocultos ao serviço, solicitou-se a interlocução de atores e líderes de Organizações Não-Governamentais (ONG) que militam na AIDS para colaborar na sua busca. Reconhecidos os colaboradores e verificado a sua correspondência aos critérios de rede e colônia, eles eram convidados a participar da pesquisa. Quanto ao número de entrevistas realizadas, obedeceu-se a uma espécie de "Iei dos rendimentos decrescentes", como alude Thompson ${ }^{15}$, ao dizer que, quando os testemunhos começam a se repetir e as denotações passam a ser constantes, está na hora de parar com as entrevistas. Foram, então, entrevistadas cinco pessoas, entre 25 e 34 anos de idade, sendo duas mulheres e três homens.

Respeitando as diretrizes e as normas que regulam as pesquisas envolvendo seres humanos, encaminhou-se o projeto de pesquisa ao Comitê de Ética em Pesquisa da Universidade Federal do Paraná, que após o seu consentimento, foi iniciada a coleta dos dados. Ressalte-se que cada colaborador recebeu e assinou o Termo de Consentimento Livre e Esclarecido contendo todas as informações necessárias à realização do estudo. Com o propósito de garantir o anonimato, foi escolhida uma ordem numérica, aleatoriamente, para cada colaborador.

Para a obtenção dos relatos, utilizaram-se perguntas norteadoras que não foram usadas rigidamente, a fim evitarem o engessamento dos relatos, mas com o intuito de "seguir uma ordem de importância de inscrever os tópicos principais em análise do depoente" 14:146.

Empreenderam-se, na pesquisa, os caminhos da análise de conteúdo descrita por M inayo ${ }^{16}$, que, segundo a autora, consiste nas seguintes fases: pré-análise, exploração do material, tratamento dos resultados e interpretação. A partir dos dados colocados estabeleceram-se as categorias e, que foram el encadas buscando um encadeamento claro das idéias. As categorias emergentes foram: As vivências diante da situação limite; A expressão da sexualidade; 0 sistema de saúde. 
As vivências diante da situação limite

A doença éum momento de transição na vida da pessoa, que desorganiza seu ser, suas relações e seus ajustamentos à vida em sociedade, e, precisamente, aqueles que estão mais próximos, como família, trabalho, amigos, lazer e paixões. Essa constatação é acompanhada de muitas incertezas, gerando ansiedade, insegurança, medo e o sentimento de perda de uma situação, por ora, conhecida para um porvir desconhecido e assustador. E é no confronto com essa nova realidade que a pessoa passa a vivenciar momentos degrande sofrimento.

0 dia que recebi meu diagnóstico foi muito difícil, me lembro como se fosse hoje. [...]A Aquele momento foi horrível [...] e fiquei com medo... (colaborador 1)

0 mundo naquela hora acabou, senti como se tivessem puxado o meu tapete. (colaboradora 3)

Em setratando especificamentedaAIDS, além das proposições supracitadas, ela comporta um julgamento moral, uma vez que é tomada como uma doença que atinge pessoas que têm um comportamento considerado transgressor e, portanto, moral esocialmentereprovável. Como conseqüência, acabagerando identidades moralmente "deterioradas"8. As falas exprimem pensamentos que'marcam' as identidades dos depoentes, como se verifica a seguir:

É difícil assumir que eu tenho AIDS, porqueme coloca em um lugar aonde as pessoas vão me ol har de forma diferente[...] écomo sefosse um ET, e por eu ter AIDS écomo seeu não fossemais eu, como se sentisse diferente, pensasse diferente e me comportasse diferente. $\mathrm{N}$ ão vão mais lembrar o que fiz de bom, e as minhas qualidades, vão sim me colocar na cruz eme apedrejar como uma pessoa desqualificada, sem valor (colaboradora 3)

N unca falei que tinha 0 vírus. [...] As pessoas são muito maldosas aqui no bairro, tem um bando de gente fofoqueira que vive falando da vida dos outros. Não quero que a minha vida vá cair na boca dessa gente maldosa. (colaboradora 2)

Esses depoimentos refletem como a pessoa portadora do HIV carrega consigo os estigmas construídos em torno da AIDS, repercutindo sobrea sua identidadee sua história devida. Relembrando os preceitos de Goffman, a pessoa estigmatizada padece de diversas conseqüências nefastas em função deste fato. Sua diferença atrai a aten ção das pessoas, afastando-as e impedindoas de perceber suas outras características, passa a não ser vista e tratada como humana e tem suas chances de vida limitadas. A ela se agrega a idéia de periculosidade einferioridade, equal quer coisa que faça para se defender será explicada pela presença do atributo estigmatizante. 0 autor complementa que, freqüentemente, a pessoa estigmatizada passa a interiorizar as mesmas crenças daqueles que a estigmatizam e, assim, não se sente 'normal' edigna de direitos eoportunidades legítimos. Passa a sentir vergonha por portar tal atributo, bem como almeja não têlo.

Outro fator significante que emergiu do conteúdo das entrevistas foi o medo perante o limiar da vida, pressentido pela proximidade da morte. A sua imagem parece ser descortinada com a revelação da sorologia positiva para o HIV, caindo por terra a sensação de imortalidade. Com efeito, aquele que se vê diante de um diagnóstico positivo para o HIV vive uma decretação de morte antecipada pela equivalência - imaginária - que é feita entre o binômio AIDS e morte ${ }^{17}$.

Eu tenho AIDS, e qual o destino de quem tem AIDS? N ão é morrer? (colaborador 1 )

A questão da morte também vem atrelada ao medo da discriminação eao sentimento deculpa.

Vivo muito triste, penso muito na minha morte, no medo de ser discriminado e carrego uma culpa que não sei de onde vem. (colaborador 1)

Percebe-se no relato desse colaborador que 0 que realmente lhe confere sofrimento é o confrontar-se com os constrangimentos impostos não pela dor infringida ao corpo doente (ser ou não ser doente de AIDS), mas pela pungência do preconceito e da discriminação decretados pelo meio externo. 0 sentimento deculpaquerefletea metáfora estigmatizante da AIDS e que se instala no imaginário social - e, portanto, não sabe de ondevem - 'celebra' a exploração moralista quese faz em torno da AIDS, castigando-o pelo seu comportamento divergente dos valores morais e sexistas da sociedade tradicional. Tal é esta condenação queo impededeserelacionar afetivamente com outras pessoas, como posto neste relato:

$\mathrm{Não}$ consigo mais me relacionar amorosamente com ninguém porque tenho medo de perder a pessoa etambém depassar para ela. Sabe como é, eu sei quea camisinha protege, mas ela podeseromper e eu contaminar a outra pessoa, e eu não quero ser responsável por isto. [...] Já basta o peso quecarrego da minha doença... (colaborador 1)

0 segundo depoente exprime os seus pensamentos em relação a sua família, guardando silêncio de sua própria dor, pelo peso da culpa:

[...]tenho momentos de grande tristeza angústia sobre o meu futuro, que gostaria de estar compartilhando com as pessoas que eu amo, mas infelizmente eu sei que se eu contar estarei fazendo-os 
sofrer por demais, e não quero ser culpado deste sofrimento. Já basta os meus problemas e eu não quero ser responsável por tantos outros que eu sei que pelo fato de ser soropositivo podem acarretar para a minha família. Estar longe de certa forma facilita a minha vida, pois eles não vêem que eu sofro, mas por outro lado sinto-me muito só, porque não tenho com que dividir a minha dor. (colaborador 4)

Ao deparar-se com o diagnóstico positivo para o HIV, a pessoa, segundo Silva ${ }^{18}$, convive com dois tipos de ansiedades: estar com a doença ou portar um vírus que demarca o limite de sua existência, acrescido da preocupação em escondêla, a todo custo, das pessoas mais próximas, principalmente dos seus familiares.

Essa questão pode estar relacionada ao fato de que a AIDS traz à tona os valores, as normase os comportamentos interiorizados no processo de socialização primária, tendo a família como o principal agente desta socialização e, portanto, quando se pensa em fazer alguma coisa ou quando algo foge aos padrões da norma apreendida, a primeira instituição a ser lembrada é a família. Destaca-sequeos colaboradores entrevistadosnão comentaram sua sorologia com seu núcleo familiar de origem (pai e mãe). Para Parker \& Aggleton ${ }^{7}$, as famílias podem rejeitar os seus membros soropositivos não só pelo fato de estarem infectados, mas também em virtude das conotações de homossexualidade, uso de drogas e promiscuidade, significados quea AIDS carrega.

\section{A expressão da sexualidade}

Valerecordar que nanossa sociedadeexistem crenças e valores relacionados à sexualidade que são resultados de inúmeras interações, e a ameaça da AIDS esbarra em muitos desses valores que se definem de forma diferenciada quando falamos de homens e mulheres. Com o seu advento, a sexualidade ficou mais exposta, deflagrando 0 impressionante critério de dois pesos e duas medidas para os valores sexuais entre os gêneros.

Pensar a questão da AIDS e da sexualidade requer, então, uma reflexão do ponto de vista das relações de gênero, como relação depoder. É, portanto, neste contexto que os dados confirmam a tese dequea vulnerabilidadedas mulheres ao HIV édecorrente não só da subordinação de sua sexualidade ao desejo masculino, como também de sua própria vivência cotidiana modelada na experiência do amor romântico ${ }^{19}$.

... o F. (marido), ele foi meu primeiro e único homem [ ...]. Sabia que de vez em quando ele usava droga, mas como eu não conhecia isto nunca pensei queel epudesseestar com o vírus da AIDS, [...] nunca tinha parado para pensar sobre isto. Acho que nunca tinha associados às coisas. $A$ gente acha que a pessoa quea gente ama não pode passar estas coisas pra gente. M esmo sabendo, eu não conseguia conversar com ele sobre isto. (colaboradora 2)

Quando se refere ao fato de o marido não querer fazer o testeanti-HIV e conseqüentemente não buscar assistência médica, justifica, também, sua não-adesão ao acompanhamento clínico, pois tem a sensação que será responsabilizada pela infecção de ambos.

Eu tenho a sensação de que se disser que tenho HIV eu serei a responsável por isto. [...]. É que vai parecer que eu é que tenho o HIV, e que eu é que passei para ele. É que parece que o primeiro que sabe que tem AIDS é o responsável por ter passado para o outro. (colaboradora 2)

Pesquisas do Programa Conjunto das Nações Unidas sobre o VIH/SIDA ${ }^{10}$ trazem exemplos importantes que reforçam os estigmas em relação ao papel de gênero, nos quais os homens são freqüentemente perdoados pelo comportamento que resultou na sua infecção, enquanto as mulheres são responsabilizadas, são abandonadas pelos maridos que as infectaram, rejeitadas pelos conhecidos e pela família. Por temerem esta trágica situação, muitas delas preferem não conhecer sua condição sorológica, ou se a conhecem, preferem mantêla em segredo.

No processo de constituição de mulher e de homem, segundo Louro ${ }^{20}$, ocorreum investimento continuado e produtivo dos sujeitos - ainda quenem sempre deforma evidentee consciente, visando à determinação de suas formas de ver ou vivenciar a sua sexualidade e seu gênero. Apesar de todas as oscilações, contradições e fragilidades que marcam o investimento cultural de uma sociedade, ela busca, intencionalmente, 'fixar' uma identidade masculina ou feminina 'normal' eduradoura. Esse intento acaba articulando as identidades ditas'normais' a um único modelo de identidade sexual, qual seja: a identidade heterossexual que é concebida como natural, universal e normal. N esse sentido, mesmo que aparentemente, supõe-se que todos os sujeitos tenham uma inclinação inata para eleger como objeto de seu desejo, como parceiro de seus afetos e de seus jogossexuais alguém do sexo oposto. Conseqüentemente, outras formas de sexualidade são constituídas como antinaturais, peculiares e anormais ${ }^{20}$.

A situação se complica ainda mais quando 
surge a epidemia da AIDS, na qual foram os homossexuais as primeiras pessoas identificadas com a doença. Dessa maneira, a epidemia e suas conseqüências tornam-se um marco histórico na vida dos mesmos, tanto do ponto de vista individual como coletivo, causando uma enorme devastação na vida afetiva e social deste segmento de pessoas.

É possível perceber, na pesquisa, a partir da fala dos colaboradores, a força dos preceitos familiares e das concepções religiosas que se interpõem nas vivências da homossexualidade e do HIV e da AIDS, e que revelam a necessidade de ocultação da orientação sexual, as culpas diante da infecção, muitas vezes associadas à noção de pecado, causando-Ihes intensos sofrimentos.

N unca abri isto para os meus pais. [...] N ão sei o que émais difícil dizer que sou gay ou setenho o HIV. (colaborador 1)

U m castigo de algo que eu fiz, mas não sei ao certo o que é. Sei lá, devo ter pecado, e muito! [...] Por ser gay egostar dehomens, acho que só podese isto. (colaborador 2)

Para finalizar a análise desta categoria, argumenta-se que administrar as inseguranças, as contradições e os temores em relação à vivência dual homossexualidade/AIDS presentes nos re latos dos colaboradores parece ser uma questão mais premente do que aquel as que dizem respeito à busca ou à afirmação de uma identidade homossexual. Conviver com a ameaça de ser descoberto desponta nesta pesquisa como um problema para muitos homens, achado que vem reforçar os estudos de Terto Jr. ${ }^{21: 99}$, quando relata que [...] são conhecidos casos de homens que preferem morrer ou não buscar acompanhamento médico adequado por medo de se expor e ser descoberto e ter de sofrer constrangimentos e acusações.

\section{O sistema de saúde}

$N$ a medida em que surgem questões que dizem respeito à assistência às pessoas portadoras do HIV e da AIDS, faz-se mister considerar o ideário do modelo de intervenção que procura colocar a AIDS na 'ordem do dia' como uma doença potencialmente controlável, a ser manejada em nível das Unidades de Saúde. Assim, ao ser encarada como tantas outras patologias de caráter evolutivo crônico, a idéia de queo acompanhamento clínico responderá satisfatoriamente a um problema de notória magnitude parece falaciosa, pois a AIDS é muito mais uma doença de âmbito social do que biológico. Daí a necessidade de considerar a complexidade deste fenômeno.

Assinalam-se tais questões visto que, a Secretaria M unicipal de Saúde de Curitiba (SM S), ao organizar o modelo de intervenção da atenção ao HIV e à AIDS, definindo as Unidades de Saúde como a 'única' porta de entrada das pessoas acometidas pela infecção ao sistema de saúde, eque a exemplo de tantas outras patologias, as pessoas portadoras do HIV recebam atendimento na unidade mais próxima de sua residên$\mathrm{cia}^{22}$, pode levá-las à clandestinidade. Isso porque elas têm receio de serem identificadas, principalmente quando sabem que nesses serviços irão encontrar pessoas de seu convívio social, tais como familiares, amigos, vizinhos ou colegas de trabalho, para quem não foi revelado seu diagnóstico de HIV. Devido a esse medo, antecipam que vão sofrer de discriminação, estigmatização e marginalização - em função da representação social da doença - e, assim, escolhem o segredo para evitar problemas que não conseguem enfrentar, fato que influenciará negativamente os cuidados de sua saúde. Acontecimentos reais, que são assinalados nos depoimentos destes colaboradores:

N unca falei que tinha o vírus, eles não sabem (os profissionais de saúde). Vou para tratar de outras coisas, mas para tratar o H IV não! Eu não consigo dizer que tenho AIDS. [...] É porque acho que eles vão pensar que sou vagabunda e vão descobrir que o F. (marido) usa drogas. Tenho medo de ser julgada, que fiquem bisbilhotando minha vida. Sabe, tem uma porção de pessoas que eu conheço e que vão ao posto, e eu acho que eles vão ficar sabendo, e eu não quero que ninguém saiba. (colaboradora 2)

$\mathrm{N}$ ão quero ir ao posto desaúde perto da minha casa, porque sou uma pessoa extremamente conhecida e se eu for eles podem meidentificar como portador do vírus HIV. Eu tenho vontade de ir a um serviço, mas não naquele que vão me identificar. (colaborador 5)

O quarto colaborador mostrou em seu relato o modo como a profissional de saúde lhe atendeu, e a forma como a mesma reagiu quando falou de sua sorologia. Ele relatou:

[...] ela me recebeu muito bem, foi super simpática, [...] me perguntou o que eu sentia, edisse que naquele momento eu estava bem, disse que tinha ido apenas para receber informações sobre o tratamento do HIV, por que eu estava com 0 vírus. Foi muito engraçado, pois a moça mudou da água para o vinho. Senti que ela se retraiu e 
começou a me fazer perguntas de ordem muito íntima, tipo: como eu tinha me infectado, quem era a pessoa, se eu só transava de camisinha, e que se eu sabia como pegava o HIV, porque não usei o preservativo? M e senti naquela hora como se estivesse em um tribunal e de novo recebendo um sentença de culpado, e pior, invadido por alguém que sequer disse o seu nome e que me perguntava tantas coisas da minha vida, que eu tenho certeza que naquela hora não fariam nenhuma diferença para mim, talvez fizessem para ela! (colaborador 4)

Interessante observar que o modo como a profissional de saúde invadiu sua privacidade questionando a forma como havia se infectado revela a visão preconceituosa do discurso biomédico no qual o portador do HIV oscila de vítima a vilão da epidemia da AIDS ${ }^{21}$. Esta situação traz como pano de fundo o desconforto que a epidemia da AIDS instal ou no discurso biomédico, situações polêmicas recheadas detabus para as quais não se encontravam preparadas, uma vez que elas não vinham sendo objeto de reflexão para o saber das ciências biomédicas ${ }^{23}$.

As questões apresentadas para a discussão sobre o sistema de saúde versam sobre a lógica da concepção do novo modelo de atenção para o enfrentamento da epidemia da AIDS e sobreas experiências vivenciadas no cotidiano das pessoas que não conseguem suplantar de forma saudável os estigmas da doença. Lançando-se mão das palavras de Raggio \& Giacomini ${ }^{24}$, parece que o novo modelo de intervenção é mais uma reoferta do velho, quesereproduz continuamente, ou seja, uma novidade vel ha, a serviço da modernização retrógrada. Pensar em um novo modelo assistencial não se restringe a treinar pessoal que mantenha a essência do historicamente modelo hegemônico, pois rapidamente se exaurem nos tributos que lhe prestam. Trata-se de habilitar prestadores, gestores e usuários para que se tornem sujeitos de um processo de construção [...]. À questão dos modelos deve se contrapor a visão de processo que negue ao setor saúde como máscara sanitária de uma soci edademórbida, produtora de doença. 24:8

Coloca-se para reflexão que o modo como se estabelece o ingresso das pessoas portadoras do HIV e da AIDS no sistema de saúde, tendo a Unidade de Saúde como única porta de entrada, revela fragilidade, pois deixa solto na ponta aqueles agentes do sistema que estão mais fragilizados e vulneráveis.
Um olhar retrospectivo sobreo percurso analítico

U tilizar o referencial metodológico dahistória oral como caminho para conhecer uma determinada faceta da realidade concreta das pessoas soropositivas para o HIV foi gratificante, pois os depoimentos orais ganharam alcance social quando os colaboradores foram inseridos nos grupos sociais que os interpretaram na medida da inscrição de cada colaborador nos grupos sociais que os explicaram, deixando de ser indivíduos atomizados e passaram a ser significados. Os motivos relatados foram analisados de modo a Ihes permitir atribuir significado social, no qual a imaginação e o simbólico almejam emergir, como preconiza o método da história oral.

A descoberta da soropositividade mostrouse um momento crítico na vida dos colaboradores, evocando sentimento de ansiedade, angústia e medo, no qual não vislumbram a possibilidade de um desfecho sereno. Há a consciência de um perigo emanado não apenas pelo significado da doença que define o limite de sua existência, mas também a possibilidade de grandes perdas que inscreverão profundas mudanças no modo como se percebem evivem; um perigo que vem de fora, dotado de uma força avassaladora, um fantasma sem face definida que está em todos os lugares e personifica uma ameaça originada pela real convivência com uma sociedade preconceituosa ediscriminatória que lhe atribui a marca da degradação. Diante desses fatos, acreditam que seu destino está traçado.

Essas situações levam as pessoas a vivenciarem emoções singulares e particulares, dependendo de suas trajetórias de vida - mas que são significadas no imaginário coletivo da AIDS - permeadas pelo medo da rejeição e do abandono, encerrando-as numa imperiosa necessi dade deocultação do diagnóstico, seja no âmbito familiar, seja nas relações sociais e de trabalho. O cultam a sua sorologia, não pela informação objetiva e afirmativa de ter um vírus, já que não éum vírus qualquer. É o HIV, que pela sua roupagem metafórica conduz a um julgamento moral ereprovável, queinvade a vida privada, revela um lado obscuro, ilícito e desvela os prazeres do corpo que excederam ao 'controle da carne.' E como o destino já está inscrito aos transgressores, sabem que serão punidos, excluídos e deverão sofrer pelo ato que cometeram. Em função dessas possibilidades geradoras de sofrimento, escolhem o segredo e muitas vezes se isolam no sentido de se proteger, pois enfrentar essas situações significa ultrapassar as forças de que dispõem. 
Evidencia-seque afamília, por escolha consciente dos colaboradores, não foi informada de sua sorologia. Fato que pode ser explicado, pois, se porventura um dos membros de uma família for portador do HIV, este acontecimento podeser um elemento desagregador que põe em risco o papel da mesma como instância de controle sobre os comportamentos, instalando-se a desordem.

A representação social que agrega a AIDS a um aspecto físico deteriorado e, conseqüentemente, ao ideário da morte no qual encontra rebôo no tipo de imagem edificada pelos meios de comunicação e reforçado pelas ciências biomédicas, tem como postulado responsabilizar a pessoa por sua debilidade física e emocional, de tal sorte quea pessoa que se descobre portadora do HIV ou doente de AIDS acaba carregando consigo, em seu imaginário, uma imagem estereotipada, na qual parece prevalecer Thánatos, ou seja, a morte, ao invés de Eros, vida, minando a cada dia de sua existência seus sonhos, seus projetos e seu poder vital ${ }^{25}$.

Outro fato importante que suscita o sentimento de medo dos colaboradores está relacionado à forma de ingresso das pessoas portadoras do HIV ao sistema de saúde de Curitiba. Em tese, o novo modelo de assistência estaria possibilitando a expansão da oferta e contribuindo para melhorar a qualidade de assistência a elas. 0 que se verifica nesta pesquisa é que elas rejeitam a lógica de ingresso do sistema manifestado pela negação em integrá-lo, ou seja, ele não está sendo legitimado justamente pela população que o modelo objetiva cuidar. Verifica-se que o modelo de assistência não está dando condições para que a pessoa tenha uma sensação de proteção e continência com a instituição que lhe aten $\mathrm{de}^{26}$.

A observância e análise em relação aos motivos que dificultam os colaboradores a buscar os serviços de saúde, quando analisados sob o prisma de um depoimento individual, distinguem-se dos demais, uma vez que a trajetória de cada pessoa, em si, é polissêmica. No entanto, como pre ceitua o método da história oral, a importância do testemunho oral pode estar não em seu apego aos fatos, mas na verdade simbólica e no imaginário, e, como local de expressão da sociedade e uma das forças reguladoras da vida coletiva, acaba explicando as atitudes individuais.

Os motivos que interferem na procura aos serviços de saúde referidos pel os colaboradores parecem ter sua gênese e explicação no modo como se deu o processo de simbolização da AIDS a fim de decifrá-la e como foi significada, quando Ihe deram um sentido profundamente depreciativo, an- corando-a no imaginário do mal, das pestes, do sexo eda morte. Estesentido éo núcleo do estigma do qual as marcas físicas e o diagnóstico positivo constituem as manifestações perceptíveis do sinal que desencadeia as condutas estigmatizantes.

Como os colaboradores desta pesquisa não revelaram sua sorologia a público e não portam os estigmas denunciados pelo corpo, como manchas na pele, emagrecimento, queda de cabelo - na medida em que são estes sinaisfísicos e o sentido atribuído a eles que provocam reações - salvo os de culpa decaráter quenão podem ser visíveis, conseguem por meio daestratégia de dissimulação, mentira, isolamento esilêncio encobrir as marcas estigmatizantes para que não venham a ser conhecidas pelos 'normais' e se manterem na posição de desacreditáveis. M as, para sustentarem esta característica precisam a todo o momento manipular a informação sobre seu defeito para que não se transforme em sinal de estigma. Por conseguinte, as atitudes denegação, isolamento eocultação da doença se desenham como forma de se proteger eevitar a 'execração pública', que se traduz no plano das relações por meio deatitudes preconceituosas, discriminatórias, cul pabilizanteseexcludentes, respostas provocadas pelo estigma.

Assim, o fato de a SM S estabelecer como estratégia a descentralização da assistência às U nidades Básicas de Saúde coloca um empecilho na vida daqueles que não querem ter a identidade de soropositivo conhecida pelas pessoas de seu convívio social. E para se proteger da rejeição, do preconceito e da discriminação, preferem não se expor, muitas vezes impedindo-os de confiar em alguém ou procurar cuidados para a sua saúde, aumentando a sua vulnerabilidade para adoecer deAIDS.

Importante registrar que os resultados que emergiram desta investigação não têm nenhuma pretensão de buscar a verdade, visto que as verdades são sempreversões. Procurou-setrazer evidências, lembrando que a análise final é fruto de um momento, de um encontro e de um recorte feito na trajetória de vida de pessoas anônimas que vivem com o HIV ou a AIDS, não podendo ser creditada como incontestável ou definitiva, pois como a própria $\mathrm{H}$ istória se modifica e se transforma. Lembra-nos M inayo ${ }^{16}$ que em se tratando de ciência, as afirmações podem superar conclusões prévias a elas e podem ser superadas por outras afirmações futuras [...], mas se mostram úteis à medida que podem contribuir para diminuir a vulnerabilidade das pessoas em relação ao sofrimento imposto pela vivência de uma doença estigmatizante. 
0 fascinante do trabalhado com esta metodologia foi à possibilidade deempreender um caminho pela temporalidade da trajetória existencial humana, e de escutar os excluídos sociais e calados pelos discursos hegemônicos, permitindo descobrir lugares onde acontecem experiências marcantes derelacionamentos humanos belos ou perversos.

Diante de algumas constatações, o fluxo da trajetória existencial humana demarcada por uma cultura que constrói significados sobre a epidemia da AIDS ancorando-os- conscienteou inconscientemente-, na desconstrução da vidae na construção da morte, na dessexualização dos corpos e adestramento das condutas, e que expressa por meio de pesos e desvalia, o destino das pessoas por ela acometidos, pode nos afligir e nos deixar perplexos ao percebermos quetambém fazemos parte. Contudo, ela jamais será intransponível ou imutável. Então, quem sabe possamos ter coragem e força de ousar buscar outras esferas do pensamento e da vida, ajudando a colaborar na luta das pessoas envolvidas. A luta pela vida, a luta pela morte longe do exílio e da solidão, a luta por uma escuta sensível, a luta pela solidariedade epelos direitos à saúde, à vida e à morte com integridade e dignidadeé, pois, a luta pela cidadania.

\section{Colaboradores}

M RCB Almeida trabal hou na concepção teórica, elaboração, redação final do texto, organização e execução da pesquisa. LM Labronici participou como orientadora durante todas as etapas da elaboração da dissertação e do artigo. 
1. Pádua IM. SIDA, doença estigmatizante: uma leitura antropológica do problema. An. Fac. Med. Univ. Fed. M inas Gerais 1986; 35(1):22-7.

2. Herzlich C, Pierret J. Uma doença no espaço público: a AIDS em seis jornais franceses. Physis Revista de saúde coletiva 1992; 2(1):7-35.

3. Daniel $H$, Parker $R$, organizadores. AIDS, a terceira epidemia: ensaios e tentativas. São Paulo: Iglu; 1991.

4. Sontag S. A AIDS e suas metáforas. Rio de Janeiro: Graal; 1989.

5. Zampiere AMF. Sociodrama construtivista da AIDS: método de construção grupal na educação preventiva da Síndrome da I munodeficiência Adquirida. São Paulo: Psy; 1996.

6. Guimarães KM, Godinho MC. Assistência psicológica. Dossiê Pela VIDDA-RJ 1992; 2 (12): p.19-20.

7. Parker R, Aggleton P. Estigma, discriminação e AIDS. Rio de Janeiro: $A B I A ; 2001$.

8. Goffman E. Estigma: notas sobre a manipulação da identidade deteriorada. Rio de Janeiro: Guanabara Koogan; 1988.

9. Parker R. O estigma e a discriminação relacionados ao HIV/AIDS. Boletim ABIA 2002; (48): 3-5.

10. Programa Conjunto das $\mathrm{N}$ ações Unidas sobre 0 VIH/SIDA. Análisis comparativo: estudios de investigación de la India y U ganda. Discriminación, estigma y negación relacionados com VIH y el SIDA. Ge nebra; 2002.

11. Programa Conjunto das $\mathrm{N}$ ações Unidas sobre 0 VIH/SIDA. Marco conceptual y base para la acción estigma y discriminación relacionados con el $\mathrm{VIH} /$ SIDA. Genebra, 2003.

12. Daniel H. A terceira epidemia: o exercício da solidariedade. In: Daniel $H$, Parker $R$ organizadores. AIDS, a terceira epidemia: ensaios e tentativas. São Paulo: Iglu; 1991. p. 13-30.

13. Queiroz MI. Relatos orais: do indizível ao dizível. In: Von Simon, 0 de M, organizadores. Experimentos com história oral. São Paulo: Vértice; 1988.

14. M eihy JCSB. Manual de história oral. 4a.ed. São Paulo: Loyola; 2002.

15. Thompson P. A voz do passado: história oral. Rio de Janeiro: Paz e Terra; 2002.
16. Deslandes SF, Cruz Neto R, Gomes R, M inayo, MCS, organizadores. Pesquisa social: teoria, método e criatividade. Petrópolis: Vozes; 1994.

17. Brasil VV. A desnaturalização da idéia da morte na AIDS. In: Lent CF, Valle A, organizadores. Enfrentando o APARTHAIDS. Rio de Janeiro: IDAC - Banco de Horas; 1996.

18. Silva LL. AIDS e homossexualidade em São Paulo [dissertação]. São Paulo (SP): Pontifícia Universidade Católica de São Paulo; 1986.

19. Fernandes M. Saúde e sexualidade da mulher presidiária em São Paulo: relato de uma experiência de prevenção do HIV/AIDS. In: Villela WV, organizador. Mulher e AIDS: ambigüidade e contradição. Cadernos NEPAIDS. São Paulo; 1997.

20. Louro GL. Pedagogias da sexualidade. In: organizador. 0 corpo educado: pedagogias da sexualidade. $2{ }^{a}$ ed. Belo Horizonte: Autêntica; 2001.p.7-34.

21. Terto Jr V. Homossexuais soropositivos e soropositivos homossexuais: questões da homossexualidade masculina em tempos de AIDS. In: Parker R, Barbosa RM, organizadores. Sexualidades brasileiras. Rio de Janeiro: Relume-Dumará: ABIA: IMS/ UERJ; 1996.p. 90-104.

22. Curitiba. Prefeitura Municipal de Curitiba. Secretaria Municipal da Saúde. Atendimento inicial ao portador do HIV em unidades básicas de saúde. Curitiba; 2002.

23. Camargo Jr KR. As ciências da AIDS \& a AIDS das ciências: discurso médico e a construção da AIDS. Rio de Janeiro: Relume-Dumará: ABIA: IMS, UERJ; 1994.

24. Raggio A, Giacomini CH. Sistema único de saúde: propósitos e processos sociais de construção. Rev Espaço para a Saúde 1995; 4(4):22-29.

25. Labronici LM. Eros propiciando a compreensão da sexualidade das enfermeiras [tese]. Florianópolis (SC): Universidade Federal de Santa Catarina; 2002.

26. Ferreira CVL. AIDS e exclusão social: um estudo clínico com pacientes HIV. São Paulo: Lemos; 2003.

Artigo apresentado em 22/06/2005

Aprovado em 23/06/2006

Versão final apresentada em 9/08/2006 